\title{
Nonalcoholic Fatty Liver Disease Alone Is a Better Predictor of Metabolic Syndrome and Insulin Resistance than Existing ATP-III Criteria
}

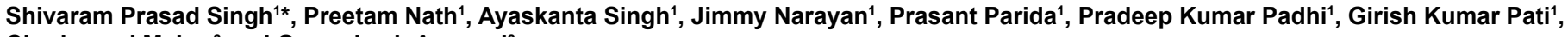
Chudamani Meher ${ }^{2}$ and Omprakash Agrawal ${ }^{2}$

${ }^{1}$ Department of Gastroenterology, S.C.B. Medical College, 753007 Cuttack, India

${ }^{2}$ Department of Radiology, Beam Diagnostics Centre, Bajrakabati Road, 753001 Cuttack, India

\begin{abstract}
Objective: Metabolic syndrome (MS) also known as insulin resistance syndrome is a surrogate marker of insulin resistance (IR). Traditionally this is being diagnosed by Adult Treatment Panel III (ATP-III) and International Federation of Diabetes (IDF) criteria. Despite mounting evidence in favor of non-alcoholic fatty liver disease (NAFLD), this has not been yet included as a component of either ATP-III or IDF criteria. We conducted this study to evaluate if NAFLD could be used as a criterion for identifying metabolic syndrome.
\end{abstract}

Methods: Setting: Single center observational study in Gastroenterology OPD at SCB Medical College, Cuttack.

Subjects: Consecutive subjects presenting with functional bowel disease were included; these included 68 NAFLD subjects and 200 subjects with normal liver on ultrasonography.

Investigations: All 268 subjects were evaluated for the presence of metabolic syndrome by ATP-III and insulin resistance by HOMA IR method. NAFLD subjects were compared with those with metabolic syndrome for presence of insulin resistance

Results: Patients with NAFLD had higher HOMA-IR than those with metabolic syndrome $(2.34 \pm 1.01$ vs $1.79 \pm 1.01 ; p<0.000)$. Presence of NAFLD can detect insulin resistance with a sensitivity of $78.0 \%$ and specificity of $86.3 \%$ with an odds ratio of $25.55(95 \% \mathrm{Cl}: 11.51-56.70)$ which is better than that of metabolic syndrome diagnosed by ATP-III criteria (sensitivity $71.43 \%$, specificity $70.32 \%$; OR: $5.92,95 \% \mathrm{Cl}: 2.99-11.74$ ). Multivariate logistic regression analysis showed that fatty liver was an independent predictor for insulin resistance and metabolic syndrome.

Conclusion: NAFLD alone is a better predictor for insulin resistance than existing ATP-III criteria. Hence NAFLD should be used as a surrogate marker for metabolic syndrome.

Keywords: Metabolic syndrome; Criterion; Fatty liver; NAFLD; Insulin resistance

Abbreviations: MS: Metabolic Syndrome; NAFLD: Nonalcoholic Fatty Liver Disease; CVD: Cardio Vascular Disease; DM: Diabetes Mellitus; NCEP: National Cholesterol Education Program; ATP-III: Adult Treatment Panel III; IDF: International Federation of Diabetes; HDL: High-Density Lipoprotein; IR: Insulin Resistance; HOMA: Homeostatic Model Assessment; SBP: Systolic Blood Pressure; DBP: Diastolic Blood Pressure; FBG: Fasting Blood Glucose; BMI: Body Mass Index; 95\% CI: 95\%Confidence Interval; PPV: Positive Predictive Value; NPV: Negative Predictive Value; LR+: Positive Likelihood Ratio; LR-: Negative Likelihood Ratio

\section{Introduction}

Metabolic syndrome is defined as a constellation of certain metabolic abnormalities that render an individual at higher risk for subsequent development of cardiovascular disease (CVD) and diabetes mellitus (DM) [1]. The concept and criteria for this syndrome were evolved by the World Health Organization in 1998 [2]. This was later modified by National Cholesterol Education Program (NCEP): Adult Treatment Panel III (ATP-III) [3] and International Federation of Diabetes (IDF) [4]. The major features of the metabolic syndrome are central obesity, hypertriglyceridemia, low high-density lipoprotein (HDL) cholesterol, hyperglycemia and hypertension. All the components of this syndrome share insulin resistance (IR) which is the common denominator and is responsible for the vascular and metabolic sequelae. Despite the increase in the prevalence of the components of the metabolic syndrome in obesity [5], all obese subjects do not develop the syndrome, and on the contrary, even some lean individuals can be insulin resistant
[6,7]. It has been observed that the liver, once fatty, is insulin resistant [8,9] and overproduces both glucose [9] and VLDL [10] leading to hyperglycemia, hypertriglyceridemia, and low HDL cholesterol concentration. Nonalcoholic fatty liver disease (NAFLD) which is considered as the hepatic manifestation of metabolic syndrome is defined as fat accumulation in the liver exceeding $5 \%$ to $10 \%$ by weight [11], as determined from the percentage of fat-laden hepatocytes by light microscopy, absence of significant alcohol abuse (not exceeding $20 \mathrm{~g} /$ day) and other viral, toxic and autoimmune etiologies. NAFLD confers upon the patient increased risk for ischemic heart disease and diabetes mellitus [11]. Inclusion of NAFLD as a criterion for metabolic syndrome has been proposed [12] but has not yet been incorporated into any criteria. Therefore, this study was planned to assess the possibility of NAFLD as a criterion to diagnose metabolic syndrome. Also, the aim of the study was to assess the validity of NAFLD alone and in combination with existing criteria to diagnose individuals with metabolic syndrome.

*Corresponding author: Shivaram Prasad Singh, Department of Gastroenterology, SCB Medical College, Cuttack 753007, Orissa, India, Tel: +91671 2505466, +91 671 2323624; E-mail: spsingh.cuttack@gmail.com

Received July 27, 2015; Accepted September 01, 2015; Published September 03, 2015

Citation: Singh SP, Nath P, Singh A, Narayan J, Parida P, et al. (2015) Nonalcoholic Fatty Liver Disease Alone Is a Better Predictor of Metabolic Syndrome and Insulin Resistance than Existing ATP-III Criteria. J Metabolic Synd 4: 183 doi:10.4172/2167-0943.1000183

Copyright: $\odot 2015$ Singh SP, et al. This is an open-access article distributed under the terms of the Creative Commons Attribution License, which permits unrestricted use, distribution, and reproduction in any medium, provided the original author and source are credited. 
Citation: Singh SP, Nath P, Singh A, Narayan J, Parida P, et al. (2015) Nonalcoholic Fatty Liver Disease Alone Is a Better Predictor of Metabolic Syndrome and Insulin Resistance than Existing ATP-III Criteria. J Metabolic Synd 4: 183. doi:10.4172/2167-0943.1000183

Page 2 of 5

\section{Subjects and Methods}

It was a single center observational study conducted in SCB Medical College. The subjects were the consecutive outpatients who attended Gastroenterology OPD for functional bowel disease from January 2012 to December 2012.

\section{Inclusion Criteria}

Consecutive outpatients who presented with functional abdominal pain (ROME III criteria) [13], functional dyspepsia (ROME III criteria) [14] and/or irritable bowel syndrome (ROME III criteria) [15] were included in this study. All these patients were in good general health, and with normal findings on medical history, physical examination, blood counts, and ultrasonography (except for fatty liver).

Exclusion Criteria- Patients who had organic gastrointestinal disease revealed by ultrasonography or gastro-duodenoscopy were excluded. Participants consuming alcohol $>20 \mathrm{~g}$ /day, having other known liver diseases (hepatitis viruses A to $\mathrm{E}$, autoimmune disease, Wilson's disease) and those on medications known to induce fatty liver or insulin sensitization such as estrogens, amiodarone, methotrexate, tamoxifen, glitazones and metformin were excluded.

An informed consent was taken from each subject. The anthropometric assessment included measurements of weight, height, and waist circumference (WC) and hip circumference (HC). The WC and $\mathrm{HC}$ were measured at the level midway between the lowest rib and the iliac crest and at the level of the great trochanter respectively. Body mass index (BMI) was calculated as weight $(\mathrm{kg}) / \mathrm{height}^{2}\left(\mathrm{~m}^{2}\right)$.

The measurements of fasting glucose, triglycerides, cholesterol, and high-density lipoprotein (HDL) cholesterol and liver function tests were performed by standard laboratory methods. Serum insulin level was estimated by electrochemiluminescence using standard kit (RocheDiagnostics, USA) with autoanalyser Elecsys 2010 (Roche-Hitachi, Japan). IR was calculated using the homeostatic model assessment (HOMA) method using a mathematical model derived from FBG and plasma insulin. The value of HOMA was calculated by the following equation: (fasting insulin $(\mu \mathrm{U} / \mathrm{ml})$ X FBG $(\mathrm{mg} / \mathrm{dl})) / 405$, and depicted as HOMA-IR value [16]. For the purpose of calculation HOMA-IR value above 2 was considered insulin resistance in our study.

The ATP III criteria [3] were used for diagnosis of metabolic syndrome (Table 1). Three or more of the five criteria were needed to be present for diagnosis of metabolic syndrome. The cut off for waist circumference taken were $80 \mathrm{~cm}$ for males and $90 \mathrm{~cm}$ for females as per the Asian population criteria [17]. Other parameters were fasting blood glucose $\geq 110 \mathrm{mg} / \mathrm{dl}$, blood pressure $\geq 130 / 85 \mathrm{mmHg}$ or treatment with antihypertensives, serum HDL cholesterol $<40 \mathrm{mg} / \mathrm{dl}$ for males and $<$ $50 \mathrm{mg} / \mathrm{dl}$ for females and serum triglycerides $\geq 150 \mathrm{mg} / \mathrm{dl}$ or patients on treatment with hypolipidemic drugs.

Trans abdominal ultrasonography was done to see fatty changes in liver. Fatty liver was defined according to the standard criteria accepted by the American Gastroenterology Association [18] i.e., an increase in hepatic echogenicity with renal echogenicity as a reference, the presence of enhancement and lack of differentiation in periportal intensity and the vascular wall due to great hyperechogenicity of the parenchyma. Ethical clearance was taken from the Institutional Ethic Committee of SCB Medical College.

\section{Statistical Analysis}

Normally distributed continuous variables were expressed as mean \pm SD. Student's t-test for unpaired data was used to compare groups when variables are normally distributed. Chi square test was used to compare differences in categorical variables. All analysis was done in software, SPSS version 16. P value of less than 0.05 was taken as significant. Logistic regression analysis was performed to assess the ability of ultrasonographic fatty liver to predict metabolic syndrome / insulin resistance after adjustment for individual ATP III criteria.

\section{Results}

A total of 316 participants were screened for the study, out of which 48 were excluded. A total of 268 subjects participated in this study, out of which 170 were males and 98 females. Metabolic syndrome was detected in 100 subjects. NAFLD was diagnosed in 68 participants.

The baseline demographic, clinical, and anthropometric and biochemical characteristics of participants having NAFLD and metabolic syndrome were compared as shown in Table 2. Patients with metabolic syndrome $(n=100)$ and NAFLD $(n=68)$ had similar gender ratio, mean age, BMI, waist circumference, blood pressure, fasting blood glucose, serum triglycerides and serum HDL cholesterol. Mean serum insulin was quite higher in NAFLD group $(9.90 \pm 3.27)$ than that of metabolic syndrome group $(7.35 \pm 3.41)$. The patients with NAFLD also had higher mean HOMA IR $(2.34 \pm 1.01$ versus $1.79 \pm 1.01)$.

Patients were classified into two groups as per their HOMA IR values. Participants with HOMA IR $<2$ were kept in first group (insulin sensitive) where as those with HOMA IR $\geq 2$ were placed in the second group (insulin resistant). 49 subjects belonged to the Insulin Resistant group and the rest to the Insulin Sensitive group. The baseline demographic, anthropometric, biochemical and sonographic characteristics between the two groups were compared in the Table 3. There was male predominance $(79.59 \%$ versus $51.89 \%, \mathrm{p}=0.006)$ in the insulin resistant group. Insulin resistant group had significantly higher mean BMI, waist and hip circumference, fasting blood glucose and serum triglycerides.

Metabolic syndrome was present in 35 (71.43\%) whereas NAFLD was detected in 38 (77.55\%) of patients with insulin resistance (IR $\geq$

\begin{tabular}{|c|c|}
\hline Risk Factor & Defining Level \\
\hline Waist Circumference & $\begin{array}{c}\text { Men }>102 \mathrm{~cm} \\
\text { Women }>88 \mathrm{~cm}\end{array}$ \\
\hline Triglycerides & $\geq 150 \mathrm{mg} / \mathrm{dL}$ \\
\hline HDL cholesterol & $\begin{array}{c}\text { Men }<40 \mathrm{mg} / \mathrm{dL} \\
\text { Women }<50 \mathrm{mg} / \mathrm{dL}\end{array}$ \\
\hline Blood pressure & $\geq 130 / 85 \mathrm{mmHg}$ \\
\hline Fasting glucose & $\geq 110 \mathrm{mg} / \mathrm{dL}$ \\
\hline
\end{tabular}

Table 1: Clinical identification of the metabolic syndrome.

\begin{tabular}{|c|c|c|}
\hline & $\begin{array}{c}\text { METABOLIC SYNDROME } \\
(\mathbf{n = 1 0 0 )}\end{array}$ & $\begin{array}{c}\text { NAFLD } \\
(\mathbf{n = 6 8 )}\end{array}$ \\
\hline Male (\%) & $60(60 \%)$ & $44(64.7 \%)$ \\
\hline Age & $44.26 \pm 12.75$ & $43.32 \pm 1.14$ \\
\hline BMI & $28.41 \pm 4.13$ & $28.47 \pm 4.02$ \\
\hline WAIST & $92.58 \pm 9.03$ & $95.21 \pm 7.98$ \\
\hline Waist Hip Ratio & $0.71 \pm 0.41$ & $0.95 \pm 0.06$ \\
\hline SBP & $133.68 \pm 14.59$ & $127.47 \pm 7.98$ \\
\hline DBP & $86.98 \pm 9.41$ & $83.00 \pm 7.37$ \\
\hline FPG & $96.94 \pm 17.64$ & $94.73 \pm 19.87$ \\
\hline Triglycerides & $194.14 \pm 67.79$ & $185.71 \pm 66.69$ \\
\hline HDL & $40.65 \pm 6.40$ & $43.95 \pm 8.92$ \\
\hline INSULIN & $7.35 \pm 3.41$ & $9.90 \pm 3.27$ \\
\hline HOMA IR & $1.79 \pm 1.01$ & $2.34 \pm 1.01$ \\
\hline
\end{tabular}

Table 2: Baseline characteristics in participants with nafld \& metabolic syndrome. 
Citation: Singh SP, Nath P, Singh A, Narayan J, Parida P, et al. (2015) Nonalcoholic Fatty Liver Disease Alone Is a Better Predictor of Metabolic Syndrome and Insulin Resistance than Existing ATP-III Criteria. J Metabolic Synd 4: 183. doi:10.4172/2167-0943.1000183

Page 3 of 5

\begin{tabular}{|c|c|c|c|}
\hline Variables & IR<2 (n=219) & $I R \geq 2(n=49)$ & $P$ Value \\
\hline Male (\%) & $131(51.89 \%)$ & $39(79.59 \%)$ & 0.006 \\
\hline Age & $41.27 \pm 14.37$ & $43.48 \pm 13.71$ & 0.316 \\
\hline BMI & 22. $07 \pm 4.63$ & $26.74 \pm 4.68$ & $<0.001$ \\
\hline WAIST & $83.17 \pm 10.07$ & $93.69 \pm 11.52$ & $<0.001$ \\
\hline HIP & $90.58 \pm 10.37$ & $100.65 \pm 9.09$ & $<0.001$ \\
\hline Waist Hip Ratio & $0.89 \pm 0.07$ & $0.96 \pm 0.07$ & $<0.001$ \\
\hline $\begin{array}{l}\text { Weight Height } \\
\text { Ratio }\end{array}$ & $0.51 \pm 0.09$ & $0.57 \pm 0.15$ & 0.001 \\
\hline SBP & $125.51 \pm 15.46$ & $129.04 \pm 13.37$ & 0.143 \\
\hline DBP & $81.34 \pm 10.22$ & $84.62 \pm 7.54$ & 0.036 \\
\hline FPG & $89.25 \pm 10.43$ & $101.23 \pm 21.79$ & $<0.001$ \\
\hline Triglycerides & $137.85 \pm 51.35$ & $199.69 \pm 73.47$ & $<0.001$ \\
\hline AST & $29.16 \pm 7.77$ & $30.87 \pm 16.00$ & 0.355 \\
\hline ALT & $33.37 \pm 12.06$ & $39.29 \pm 19.61$ & 0.025 \\
\hline HDL & $44.95 \pm 8.05$ & $42.21 \pm 8.12$ & 0.031 \\
\hline INSULIN & $5.21 \pm 2.19$ & $11.13 \pm 3.12$ & $<0.001$ \\
\hline MS (ATP III) & 65 (27.39\%) & 35 (71.43\%) & $<0.001$ \\
\hline Fatty Liver & 30 (13.69\%) & 38 (77.55\%) & $<0.001$ \\
\hline
\end{tabular}

Table 3: Baseline characteristics of study subjects according to homa-ir index.

\begin{tabular}{|c|c|c|c|c|}
\hline & $\begin{array}{l}\text { METABOLIC } \\
\text { SYNDROME }\end{array}$ & NAFLD & $\begin{array}{c}\text { NAFLD + } 2 \\
\text { METABOLIC } \\
\text { SYNDROME } \\
\text { Criteria }\end{array}$ & $\begin{array}{c}\text { NAFLD + } 1 \\
\text { METABOLIC } \\
\text { SYNDROME } \\
\text { Criteria }\end{array}$ \\
\hline $\begin{array}{c}\text { Sensitivity } \\
(95 \% \mathrm{Cl})\end{array}$ & $\begin{array}{c}71.43 \% \\
(56.74-83.40)\end{array}$ & $\begin{array}{c}78.00 \% \\
(64.03-88.46)\end{array}$ & $\begin{array}{c}67.35 \% \\
(52.46-80.04)\end{array}$ & $\begin{array}{c}73.47 \% \\
(58.92-85.04)\end{array}$ \\
\hline $\begin{array}{c}\text { Specificity } \\
(95 \% \mathrm{Cl})\end{array}$ & $\begin{array}{c}70.32 \% \\
(63.79-76.29)\end{array}$ & $\begin{array}{c}86.30 \% \\
(81.02-90.56)\end{array}$ & $\begin{array}{c}89.11 \% \\
(83.97-93.05)\end{array}$ & $\begin{array}{c}86.63 \% \\
(81.15-91.00)\end{array}$ \\
\hline $\begin{array}{c}\text { PPV } \\
(95 \% \mathrm{Cl})\end{array}$ & $\begin{array}{c}35.00 \% \\
(25.73-45.19)\end{array}$ & $\begin{array}{c}56.52 \% \\
(44.04-68.42)\end{array}$ & $\begin{array}{c}60.00 \% \\
(45.91-72.97)\end{array}$ & $\begin{array}{c}57.14 \% \\
(44.05-69.54)\end{array}$ \\
\hline $\begin{array}{c}\text { NPV } \\
(95 \% \mathrm{Cl})\end{array}$ & $\begin{array}{c}91.67 \% \\
(86.41-95.37)\end{array}$ & $\begin{array}{c}94.50 \% \\
(90.37-97.22)\end{array}$ & $\begin{array}{c}87.08 \% \\
(87.08-95.26)\end{array}$ & $\begin{array}{c}93.09 \% \\
(88.46-96.26)\end{array}$ \\
\hline $\begin{array}{c}\text { LR+ } \\
(95 \% \text { Cl) }\end{array}$ & $\begin{array}{c}2.41 \\
(1.84-3.15)\end{array}$ & $\begin{array}{c}5.69 \\
(3.96-8.19)\end{array}$ & $\begin{array}{c}6.18 \\
(3.98-9.60)\end{array}$ & $\begin{array}{c}5.50 \\
(3.72-8.11)\end{array}$ \\
\hline $\begin{array}{c}\text { LR- } \\
(95 \% \mathrm{Cl})\end{array}$ & $\begin{array}{c}0.41 \\
(0.26-0.64)\end{array}$ & $\begin{array}{c}0.25 \\
(0.15-0.43)\end{array}$ & $\begin{array}{c}0.37 \\
(0.24-0.55)\end{array}$ & $\begin{array}{c}0.31 \\
(0.19-0.49)\end{array}$ \\
\hline
\end{tabular}

Cl: Confidence Interval, PPV: Positive Predictive Value, NPV: Negative Predictive Value,

LR+: Positive Likelihood Ratio, LR-: Negative Likelihood Ratio

Table 4: Diagnostic ability of metabolic syndrome criteria and nafld to detect ir (ir $\geq 2$ )

2). $35 \%$ of participants with metabolic syndrome had IR $\geq 2$ where as $55.9 \%$ of participants who had NAFLD were insulin resistant (IR $\geq 2$ ). This reflects higher diagnostic ability of NAFLD in predicting IR than metabolic syndrome. To assess the validity of employing NAFLD to detect IR, we compared the diagnostic abilities of ATP III criteria for metabolic syndrome and presence of NAFLD for detection of Insulin Resistance (IR $\geq 2$ ) (Table 4). NAFLD with any one or two of these criteria were also compared with existing ATP III criteria of metabolic syndrome and with NAFLD alone. While the sensitivity and specificity of ATP III criteria for metabolic syndrome to detect insulin resistance were $71.43 \%$ and $70.32 \%$ respectively, NAFLD alone had a sensitivity of $78.00 \%$ and specificity of $86.30 \%$ which was quite higher than that of ATP III criteria. Addition of one ATP III criterion to NAFLD increased specificity slightly but at a lower sensitivity. Addition of two metabolic syndrome criteria to NAFLD resulted in further decline in sensitivity with additional improvement in specificity (Table 4).

Out of 49 subjects with insulin resistance, 38 had NAFLD. Insulin Resistant participants with and without NAFLD were compared in Table 5. The baseline demographic, clinical, and anthropometric and biochemical characteristics were compared between these two groups
(Table 3). No statistical significance was observed between the two groups except BMI.

The odds ratio for ATP III criteria, NAFLD alone, NAFLD with any one of the ATP III criteria and NAFLD with any two ATP III criteria for detection of IR was calculated (Table 6). NAFLD alone had a higher odds ratio of detecting insulin resistance $(25.55,95 \% \mathrm{CI}: 11.51-56.70)$ than NAFLD + 1 ATP III criterion (22.89, 95\%CI:10.6 -49.39) followed by NAFLD + 2 ATP III criteria (21.37, 95\%CI:10.03-45.51) and ATP III criteria (5.92, 95\%CI:2.99-11.74).

Multivariate logistic regression was done to assess the adjusted odds ratio for detection of insulin resistance (Table 7). After adjustment for blood pressure, fasting plasma glucose, serum triglycerides, serum HDL and waist circumference, fatty liver was found to be an independent predictor for insulin resistance.

\section{Discussion}

Metabolic syndrome is a cluster of metabolic factors which has increased cardiovascular risk and shares the hallmark of insulin resistance. Identification and early treatment of insulin resistance is important because it is an independent predictor of cardiovascular disease and type 2 diabetes mellitus [19-21]. NAFLD predicted incident diabetes independent of classic risk factors in large prospective cohort studies and may therefore be an early marker of mechanism predisposing to future metabolic events [22,23]. NAFLD is also being recognized as an indicator of early atherosclerosis. Elevated liver enzymes and hepatic steatosis on liver histology predict incident

\begin{tabular}{|c|c|c|c|}
\hline Variables & $\begin{array}{c}\text { IR>2 } \mathbf{w i t h ~ N A F L D ~} \\
(\mathbf{n}=\mathbf{3 8})\end{array}$ & $\begin{array}{c}\text { IR>2 } \\
\text { without NAFLD } \\
(\mathbf{n = 1 1 )}\end{array}$ & P Value \\
\hline Male (\%) & $28(73.68 \%)$ & $11(100 \%)$ & 0.058 \\
\hline Age & $43.36 \pm 11.87$ & $43.27 \pm 19.30$ & 0.984 \\
\hline BMI & $28.13 \pm 3.75$ & $21.03 \pm 3.55$ & $<0.001$ \\
\hline SBP & $129.05 \pm 14.05$ & $130.00 \pm 10.95$ & 0.838 \\
\hline DBP & $84.00 \pm 7.33$ & $87.27 \pm 7.86$ & 0.206 \\
\hline FPG & $101.34 \pm 23.73$ & $99.72 \pm 13.41$ & 0.831 \\
\hline Triglycerides & $199.50 \pm 72.22$ & $196.73 \pm 78.86$ & 0.913 \\
\hline HDL & $42.50 \pm 8.69$ & $40.81 \pm 5.43$ & 0.548 \\
\hline INSULIN & $11.36 \pm 3.44$ & $10.56 \pm 1.33$ & 0.456 \\
\hline HOMA IR & $2.84 \pm 1.08$ & $2.57 \pm 0.35$ & 0.423 \\
\hline MS (ATP III) & $29(76.32 \%)$ & $6(54.55 \%)$ & 0.152 \\
\hline
\end{tabular}

Table 5: Comparison of IR participants with or without NAFLD.

\begin{tabular}{|c|c|c|c|}
\hline & Odds Ratio & $\mathbf{9 5 \%} \mathbf{~ C I}$ & P Value \\
\hline METABOLIC SYNDROME & 5.92 & $2.99-11.74$ & $<\mathbf{0 . 0 0 1}$ \\
\hline NAFLD & 25.55 & $11.51-56.70$ & $<\mathbf{0 . 0 0 1}$ \\
\hline NAFLD + 1 ATP III Criteria & 22.89 & $10.61-49.39$ & $<\mathbf{0 . 0 0 1}$ \\
\hline NAFLD + 2 ATP III Criteria & 21.37 & $10.03-45.51$ & $<\mathbf{0 . 0 0 1}$ \\
\hline
\end{tabular}

Table 6: Odds ratio for detection of insulin resistance.

\begin{tabular}{|c|c|c|}
\hline & Odds Ratio (P Value) & $\begin{array}{c}\text { Adjusted Odds Ratio* (P } \\
\text { Value) }\end{array}$ \\
\hline Blood pressure & $0.541 \quad(0.069)$ & $0.643 \quad(0.313)$ \\
\hline FPG & $0.260 \quad(<0.001)$ & $0.187 \quad(0.001)$ \\
\hline TG & $0.197 \quad(<0.001)$ & $0.363 \quad(0.030)$ \\
\hline HDL & $0.519(0.055)$ & $0.856 \quad(0.716)$ \\
\hline Waist Circumference & $0.263 \quad(<0.001)$ & $1.619 \quad(0.364)$ \\
\hline Fatty Liver & $17.914 \quad(<0.001)$ & $1.847 \quad(<0.001)$ \\
\hline
\end{tabular}

${ }^{*}$ Calculated by Logistic Regression analysis

Table 7: Odds ratio of individual atp iii criteria and fatty liver for detection of insulin resistance. 
cardiovascular disease independent of traditional risk factors and metabolic syndrome. It is being increasingly postulated that the vessels and the liver share common inflammatory mediators [24,25] which leads to atherosclerosis and cardiovascular disease.

It can be interpreted from our observations that individuals with insulin resistance are more likely to have central obesity, hyperglycemia, hypertriglyceridemia, hypertension and low serum HDL cholesterol. Incidence of NAFLD and metabolic syndrome are higher in insulin resistant persons.

The objective of the ATP III criteria [3] is to identify the individuals at increased risk for development of cardiovascular disease and diabetes. The current ATP III criteria were selected because they tend to cluster together, share insulin resistance as the common denominator and are individually associated with an increased coronary risk. Due to the low sensitivity, some cases of insulin resistance remain undiagnosed, especially in nonobese nondiabetic subjects, in whom the diagnosis of metabolic syndrome is less assisted by obesity and plasma glucose criteria. Our study has shown that fatty liver is an excellent marker of metabolic syndrome and insulin resistance. Fatty liver alone was superior to ATP-III criteria in diagnosing insulin resistance. The sensitivity and specificity of ATP III criteria for metabolic respectively, NAFLD alone had a sensitivity of $78.00 \%$ and specificity of $86.30 \%$ which was quite higher than that of ATP III criteria. Thus inclusion of fatty liver into the existing criteria is strongly suggested, which can help to identify more patients who are at increased risk for the consequences of metabolic syndrome. An earlier study by Musso et al. had assessed the strength of the associations of ATP III criteria and of NAFLD to insulin resistance, oxidative stress, and endothelial dysfunction in nonobese nondiabetic subjects and showed that NAFLD was more tightly associated with insulin resistance and with markers of oxidative stress and endothelial dysfunction than ATP III criteria [26].

Marchesini et al. showed that insulin resistance was the most important finding, closely associated with the presence of NAFLD in a large series of patients, irrespective of BMI, fat distribution or glucose tolerance [27]. A study from coastal eastern India has shown that both in NAFLD patients, insulin resistance was closely associated not only with fatty liver but also histologically severe disease [28]. Thus, NAFLD might represent another feature of the metabolic syndrome, with decreased insulin sensitivity being the common factor [29]. The strong association of NAFLD with other features of the metabolic syndrome (obesity, central fat distribution, diabetes, dyslipidemia, hypertension, and atherosclerotic cardiovascular disease) further supports this hypothesis [30,31]. Various pathogenic mechanism(s) has been postulated regarding this association between NAFLD and insulin resistance. Impaired hepatic lipid and lipoprotein handling and increased oxidative stress may enhance liver fat accumulation and lead to insulin resistance by nuclear factor- $\mathrm{kB}$ pathway activation [32-34]. The findings of the study suggest that hepatic fat accumulation is more tightly related to insulin resistance than visceral adiposity, as estimated by waist circumference or any other feature of the metabolic syndrome, as defined by ATP III criteria.

A Japanese study conducted on 4401 employees without liver disease or drug treatment (mean age 48 years, BMI $23 \mathrm{~kg} / \mathrm{m} 2$ ) revealed that the odds ratios of men and women with NAFLD to develop the metabolic syndrome (ATP III criteria) during the follow-up were 4.0 and 11.2 after adjustment for age, alcohol intake, and changes in body weight [35]. Similar data have been reported by Schindhelm et al and Hanley et al. [36,37]. Likewise, in a study of 2839 type 2 diabetic outpatients with NAFLD, the risk of cardiovascular disease was significantly increased in NAFLD patients after adjustment for all components of the metabolic syndrome [38]. In a Swedish study of 129 consecutive biopsy-proven NAFLD patients followed for 13.7 years, mortality from cardiovascular (15.5\% versus $7.5 \%)$ and liver-related ( $2.8 \%$ versus $0.2 \%)$ causes was significantly higher compared with a matched reference-population (control) [39].

Early identification of subjects with insulin resistance, a high cardiometabolic risk factor, may facilitate earlier lifestyle modifications and pharmacological interventions. Consistently, therapeutic measures in NAFLD improve insulin sensitivity and cardiovascular risk profile, the ultimate goal of a diagnosis of metabolic syndrome $[40,41]$.

The study is not without limitations. As an observational study, this study is limited by selection and confounding bias. Presence of an age sex matched control could have strengthened the study. Markers of inflammation like Adipokines and cytokines and markers of endothelial dysfunction like carotid intima thickness were not measured due to resource constraint setting. Liver histopathological study was also not done in the NAFLD patients, which could have shown whether simple steatosis or necroinflammation or fibrosis were risk factors for decrease in insulin sensitivity.

\section{Conclusion}

Direct comparison between NAFLD and ATP III criteria revealed that the former is better indicator for detection of insulin resistance. Addition of one or two ATP criteria to NAFLD does not add much to the diagnostic accuracy. It can be concluded that NAFLD should not be considered as a mere hepatic manifestation of metabolic syndrome. It is an important predictor of insulin resistance. It should be included as a criterion along with the existing criteria to identify metabolic syndrome.

\section{References}

1. Haffner SM (2000) Obesity and the metabolic syndrome: the San Antonio Heart Study. Br J Nutr 83: 67-70.

2. Alberti KG, Zimmet PZ (1998) Definition, diagnosis and classification of diabetes mellitus and its complications, part 1: diagnosis and classification of diabetes mellitus provisional report of a WHO consultation. Diabet Med 15: 539-553.

3. National Cholesterol Education Program (NCEP) Expert Panel on Detection Evaluation, and Treatment of High Blood Cholesterol in Adults (Adult Treatment Panel III) (2002) Third Report of the National Cholesterol Education Program (NCEP) Expert Panel on Detection, Evaluation, and Treatment of High Blood Cholesterol in Adults (Adult Treatment Panel III) final report. Circulation 106: 3143-3421A.

4. Alberti KG, Zimmet P, Shaw J, IDF Epidemiology Task Force Consensus Group (2005) The metabolic syndrome: a new worldwide definition. Lancet 366: 1059-1062.

5. Singh SP, Kar SK, Panigrahi MK, Misra B, Pattnaik K, et al. (2013) Profile of patients with incidentally detected nonalcoholic fatty liver disease (IDNAFLD) in coastal eastern India. Trop Gastroenterol 34: 144-152.

6. Bhat G, Baba CS, Pandey A, Kumari N, Choudhuri G (2013) Insulin resistance and metabolic syndrome in nonobese Indian patients with non-alcoholic fatty liver disease. Trop Gastroenterol 34: 18-24.

7. Masharani UB, Maddux BA, Li X, Sakkas GK, Mulligan K, et al. (2011) Insulin Resistance in Non-Obese Subjects Is Associated with Activation of the JNK Pathway and Impaired Insulin Signaling in Skeletal Muscle. PLoS ONE 6: e19878.

8. Ryysy L, Hakkinen AM, Goto T, Vehkavaara S, Westerbacka J, et al. (2000) Hepatic fat content and insulin action on free fatty acids and glucose metabolism rather than insulin absorption are associated with insulin requirements during insulin therapy in type 2 diabetic patients. Diabetes 49: 749-758.

9. Seppala-Lindroos A, Vehkavaara S, Hakkinen AM, Goto T, Westerbacka J, et al. (2002) Fat accumulation in the liver is associated with defects in insulin suppression of glucose production and serum free fatty acids independent of obesity in normal men. J Clin Endocrinol Metab 87: 3023-3028. 
Citation: Singh SP, Nath P, Singh A, Narayan J, Parida P, et al. (2015) Nonalcoholic Fatty Liver Disease Alone Is a Better Predictor of Metabolic Syndrome and Insulin Resistance than Existing ATP-III Criteria. J Metabolic Synd 4: 183. doi:10.4172/2167-0943.1000183

10. Adiels M, Taskinen MR, Packard C, Caslake MJ, Soro-Paavonen A, et al. (2006) Overproduction of large VLDL particles is driven by increased liver fat content in man. Diabetologia 49: 755-765

11. Chalasani N, Younossi Z, Lavine JE, Diehl AM, Brunt EM, et al. (2012) The Diagnosis and Management of Non-Alcoholic Fatty Liver Disease: Practice Guideline by the American Association for the Study of Liver Diseases, American College of Gastroenterology, and the American Gastroenterological Association. Hepatology 55: 2005-2023.

12. Giovanni M, Roberto G, Simona B, Barbara U, Giampaolo B, et al. (2008) Should Nonalcoholic Fatty Liver Disease Be Included in the Definition of Metabolic Syndrome? A cross-sectional comparison with Adult Treatment Panel III criteria in nonobese nondiabetic subjects. Diabetes Care 31: 562-568.

13. Drossman D, Li Z, Andruzzi E, Temple RD, Talley NJ, et al. (1993) U.S householder survey of functional gastrointestinal disorders: Prevalence, sociodemography, and health impact. Dig Dis Sci 38: 1569-1580.

14. Tack J, Talley NJ, Camilleri M, Holtmann G, Hu P, et al. (2006) Functiona gastroduodenal disorders. Gastroenterology 130: 1466-1479.

15. Longstreth GF, Thompson WG, Chey W, Houghton LA, Mearin F, et al. (2006) Functional bowel disorders. Gastroenterology 130: 1480-1491.

16. Matthews DR, Hosker JP, Rudenski AS, Naylor BA, Treacher DF, et al. (1985) Homeostasis Model Assessment: Insulin Resistance and Beta Cell Function from Fasting Plasma Glucose and Insulin Concentrations in Man. Diabetologia 28: $412-419$.

17. Misra A, Vikram NK, Gupta R, Pandey RM, Wasir JS, et al. (2006) Wais circumference cutoff points and action levels for Asian Indians for identification of abdominal obesity. Int J Obes (Lond) 30: 106-111.

18. Gore RM (1994) Diffuse liver disease. In: Gore RM, Levine MS, Laufer.I, eds. Textbook of gastrointestinal radiology. WB Saunders, Philadelphia.

19. Saely CH, Aczel S, Marte T, Langer P, Hoefle G, et al. (2005) The metabolic syndrome, insulin resistance, and cardiovascular risk in diabetic and nondiabetic patients. J Clin Endocrinol Metab 90: 698-703.

20. Resnick HE, Jones K, Ruotolo G, Jain AK, Henderson J, et al. (2003) Strong Heart Study: insulin resistance, the metabolic syndrome, and risk of inciden cardiovascular disease in nondiabetic American Indians: the Strong Heart Study. Diabetes Care 26: 861-867.

21. Bonora E, Kiechl S, Willeit J, Oberhollenzer F, Egger G, et al. (2007) Insulin resistance as estimated by homeostasis model assessment predicts incident symptomatic cardiovascular disease in Caucasian subjects from the general population: the Bruneck study. Diabetes Care 30: 318-324.

22. Yokoyama H, Emoto M, Fujiwara S, Motoyama K, Morioka T, et al. (2003) Quantitative insulin sensitivity check index and the reciprocal index of homeostasis model assessment in normal range weight and moderately obese type 2 diabetic patients. Diabetes Care 26: 2426-2432.

23. Sattar N, Scherbakova O, Ford I, O'Reilly DSJ, Stanley A, et al. (2004) Elevated alanine aminotransferase predicts new-onset type 2 diabetes independently of classical risk factors, metabolic syndrome, and C-reactive protein in the West of Scotland Coronary Prevention Study. Diabetes 53: 2855-2860.

24. Schindhelm RK, Dekker JM, Nijpels G, Bouter LM, Stehouwer CD, et al. (2007) Alanine aminotransferase predicts coronary heart disease events: a 10-year follow-up of the Hoorn Study. Atherosclerosis 191: 391-396.

25. Targher G, Bertolini L, Poli F, Rodella S, Scala L, et al. (2005) Nonalcoholic fatty liver disease and risk of future cardiovascular events among type 2 diabetic patients. Diabetes 54: 3541-3546.

26. Musso G, Gambino R, Bo S, Uberti B, Biroli G, et al. (2008) Should Nonalcoholic
Fatty Liver Disease Be Included in the Definition of Metabolic Syndrome? A cross-sectional comparison with Adult Treatment Panel III criteria in nonobese nondiabetic subjects. Diabetes Care 31:562-568.

27. Marchesini G, Brizi M, Morselli-Labate AM, Bianchi G, Bugianesi E, et al. (1999) Association of non-alcoholic fatty liver disease to insulin resistance. Am J Med 107: 450-455.

28. Singh SP, Singh A, Pati G, Misra B , Misra D, et al. (2014) A Study of Prevalence of Diabetes and Prediabetes in Patients of Non-Alcoholic Fatty Liver Disease and the Impact of Diabetes on Liver Histology in Coastal Eastern India. Journal of Diabetes Mellitus 4: 290-296.

29. Cortez-Pinto H, Camilo ME, Baptista A, De Oliveira AG, De Moura MC (1999) Non-alcoholic fatty liver: another feature of the metabolic syndrome? Clin Nutr 18: $353-358$

30. DeFronzo RA, Ferrannini E (1991) Insulin resistance: a multifaceted syndrome responsible for NIDDM, obesity, hypertension, dyslipidemia, and atherosclerotic cardiovascular disease. Diabetes Care 14: 173-194.

31. Musso G, Gambino R, Durazzo M, Biroli G, Carello M, et al. (2005) Adipokines in NASH: postprandial lipid metabolism as a link between adiponectin and liver disease. Hepatology 42: 1175-1183.

32. Musso G, Cassader M, Gambino R, Durazzo M, Pagano G (2006) Association between postprandial LDL conjugated dienes and the severity of liver fibrosis in NASH. Hepatology 43: 1169-1170.

33. Pan M, Cederbaum Al, Zhang YL, Ginsberg HW, Williams KJ, et al. (2004) Lipid peroxidation and oxidant stress regulate hepatic apolipoprotein $\mathrm{B}$ degradation and VLDL production. J Clin Invest 113: 1277-1287.

34. Gambino R, Cassader M, Pagano G, Durazzo M, Musso G (2007) Polymorphism in microsomal triglyceride transfer protein: a link between liver disease and atherogenic postprandial lipid profile in NASH? Hepatology 45: 1097-1107.

35. Hamaguchi M, Kojima T, Takeda N, Nakagawa T, Taniguchi H, et al. (2005) The metabolic syndrome as a predictor of nonalcoholic fatty liver disease. Ann Intern Med 143: 722-728.

36. Schindhelm RK, Diamant M, Dekker JM, Tushuizen ME, Teerlink T, et al. (2006) Alanine aminotransferase as a marker of non-alcoholic fatty liver disease in relation to type 2 diabetes mellitus and cardiovascular disease. Diabetes Metab Res Rev 22: 437-443.

37. Hanley AJ, Williams K, Festa A, Wagenknecht LE, D'Agostino RB Jr, et al. (2005) Liver markers and development of the metabolic syndrome: the insulin resistance atherosclerosis study. Diabetes 54: 3140-3147.

38. Targher G, Bertolini L, Padovani R, Rodella S, Tessari R, et al. (2007) Prevalence of nonalcoholic fatty liver disease and its association with cardiovascular disease among type 2 diabetic patients. Diabetes Care 30: 1212-1218.

39. Ekstedt M, Franzen LE, Mathiesen UL, Thorelius L, Holmqvist M, et al. (2006) Long-term follow-up of patients with NAFLD and elevated liver enzymes. Hepatology 44: 865-873.

40. Gerstein HC, Yusuf S, Bosch J, Pogue J, Sheridan P, et al. (2006) Effect of rosiglitazone on the frequency of diabetes in patients with impaired glucose tolerance or impaired fasting glucose: a randomised controlled trial. Lancet 368: 1096-1105

41. Huang MA, Greenson JK, Chao C, Anderson L, Peterman D, et al. (2005) One-year intense nutritional counseling results in histological improvement in patients with non-alcoholic steatohepatitis: a pilot study. Am J Gastroenterol 100: $1072-1081$. 